\title{
Demonstration of oestrogens in developing pig trophectoderm and yolk sac endoderm between Days 10 and 16
}

\author{
G. J. King and C. A. Ackerley* \\ Department of Animal \& Poultry Science and ${ }^{*}$ College of Biological Science, University of Guelph, \\ Guelph, Ontario, Canada, NIG 2WI
}

\begin{abstract}
Summary. Segments of individual blastocysts collected on Days 10,12, 14 and 16 were examined microscopically to observe yolk-sac development and treated immunocytochemically to localize oestrogens in specific membranes. Mesoderm was present beneath the embryonic disc of ovoid blastocysts on Day 12. The mesoderm spread beyond $1 \mathrm{~cm}$ from the disc on Day 14, producing a splanchnic yolk-sac membrane extending across the blastocoelomic cavity, but no mesodermal cells had yet reached 5 $\mathrm{cm}$. By Day 16, proliferation of mesoderm and development of the yolk sac had progressed beyond $20 \mathrm{~cm}$ from the disc in most of the specimens examined. Incubation of ultrathin sections with sheep antiserum to oestrone or oestradiol-17 $\beta$ followed by rabbit anti-ovine IgG-gold complex and subsequent counting of gold particles retained over the tissues gave a weakly positive reaction for oestrone in trophectodermal cells on Day 10. The most intense reaction for oestradiol-17 $\beta$ was also present in the trophectoderm and yolk-sac endoderm on Days 12, 14 and 16.
\end{abstract}

\section{Introduction}

Embryonic signals and maternal responses begin shortly after fertilization and continue throughout gestation. In the earliest stages of pregnancy, pig conceptuses must interact with the uterus to migrate through the lumen and achieve relatively uniform spacing, prevent immune rejection, stimulate histotroph production, maintain elevated plasma progesterone and develop placentae. Pig blastocysts acquire the ability to produce oestrogens during the period when these interactions occur and these steroids may have important biological roles in maintaining pregnancy (Perry, Heap \& Amoroso, 1973; Robertson \& King, 1974).

Silastic beads impregnated with oestradiol-17 $\beta$ migrate from the site of insertion near the uterotubal junction down the horn and through the uterine body while cholesterol-impregnated beads remain in the upper quarter or half of the horn, indicating a probable involvement of oestradiol in migration (Pope, Maurer \& Stormshak, 1982). The intrauterine administration of small amounts of oestradiol-17 $\beta$ from Days 11 to 15 increases uterine blood flow and assists in the maintenance of luteal function through a local and systemic effect (Ford, Magness, Farley \& Van Orden, 1982). Pig blastocysts synthesize oestrogens in vitro from about Day 12 (Perry, Heap, Burton \& Gadsby, 1976) but increased concentrations of oestradiol-17 $\beta$ and oestrone can be detected in uterine lymph of pregnant gilts on Days 11, 13 and 16 (Magness \& Ford, 1982). Oestrogens are therefore present when many of the early conceptus-maternal interactions occur. This study was conducted to localize and partly quantitate oestrone and oestradiol-17 $\beta$ in pig embryonic membranes as the mesoderm and yolk sac developed, from just before (Days 10 and 12) to after (Days 14-16) elongation. 


\section{Materials and Methods}

Routine processing. Immediately after exsanguination, the uteri were removed from sows slaughtered on Days 10,12,14 and 16 of gestation (day of first oestrus detection and mating = Day 0 ). The uterine horns were dissected free from the broad ligaments and opened longitudinally along the antimesometrial borders. Opened horns were placed in a tray with the mucosal side up and immersed in phosphate-buffered saline ( $\mathrm{pH} 7 \cdot 2,0 \cdot 1 \mathrm{M}$ ) (PBS) so that individual conceptuses could be located and recovered. Entire Day-10 and -12 blastocysts and segments of the chorionic vesicles collected through the embryonic disc, $1,5,10,15$ and $20 \mathrm{~cm}$ away from the disc, and at the tip on Days 14 and 16 (4-8 blastocysts/day) were transferred to fixative containing $3 \%$ glutaraldehyde in $0.1 \mathrm{M}$-phosphate buffer, $\mathrm{pH} \mathrm{7.4}$. After $2 \mathrm{~h}$ in the initial fixative at $5^{\circ} \mathrm{C}$, tissue specimens were rinsed three times for $10 \mathrm{~min}$ each in phosphate buffer, dehydrated through an ascending series of alcohols, through propylene oxide, embedded in araldite CY212 and used for immunocytochemistry as described below. A few specimens from each series were post-fixed in osmium tetroxide for conventional microscopy. Semithin sections of the osmicated tissues were stained with toluidine blue for examination by light microscopy and thin sections were stained with uranyl acetate and lead citrate for electron microscopy.

Immunocytochemistry for localization of oestrone and oestradiol-173. Gold sols were prepared according to the method of Frens (1973) and rabbit anti-sheep IgG or rabbit anti-porcine IgG (Miles Laboratories, Rexdale, Canada) were absorbed to gold particles approximately $20 \mathrm{~nm}$ in diameter at pH 7.6 (Geoghegan \& Ackerman, 1977; Larson, 1979). Blocks of glutaraldehyde-fixed material were trimmed to provide specimens of the blastocyst walls on Days 10 and 12; crosssections at $1 \mathrm{~cm}$ from the disc and near the tip of the chorionic vesicle on Day 14; and segments of the trophectoderm or yolk-sac membrane at 1,10 or $20 \mathrm{~cm}$ from the disc on Day 16. Sections exhibiting a pale gold interference colour were cut and mounted on carbon parlodion-coated 150mesh nickel grids. The section-covered grids were etched for $10 \mathrm{~min}$ in $1 \%$ hydrogen peroxide, thoroughly rinsed in distilled water and floated on a $1 \%$ solution of bovine serum albumin in

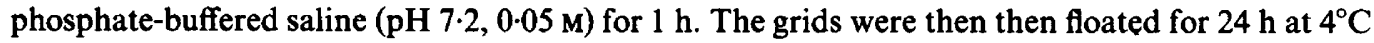
on solutions containing antiserum to oestrone or oestradiol-17 produced in sheep (Robertson, Dwyer \& King, 1980), diluted 1:20 with PBS. After a thorough rising with $0.1 \mathrm{M}-\mathrm{PBS}$, the grids were floated on anti-sheep IgG-gold or anti-porcine IgG-gold complexes, diluted $1: 1$ with PBS, for $2 \mathrm{~h}$ at $25^{\circ} \mathrm{C}$. The grids were then submitted to a mild fixation in $0.1 \%$ glutaraldehyde in $0.1 \mathrm{M}-\mathrm{PBS}$ for $30 \mathrm{~min}$ and stained in uranyl acetate and lead citrate before observation in a scanning transmission electron microscope equipped with an energy dispersive $\mathrm{X}$-ray spectrometer.

In addition to the anti-porcine IgG-gold complex, controls included exclusion of or heating anti-oestrone serum to $100^{\circ} \mathrm{C}$ for $20 \mathrm{~min}$ before incubation, and substitution of colloidal gold stabilized with $1 \%$ polyethylene glycol in place of the gold-labelled anti-immunoglobulin after treatment with anti-oestrogens.

Quantitative morphometric analysis was conducted on 25 random fields for each treatment specimen and 10 fields for each control. Individual sections from each of the selected blocks were incubated with anti-oestrone or oestradiol-17 $\beta$ serum and the same numbers of cells were analysed for each anti-oestrogen reaction within a particular region. Negative images were projected onto a digitized tablet (Datagraphics Ltd, Ottawa, Canada) and areas of interest defined with the image analysis system. The numbers of gold particles over the cytoplasm were counted. Energy dispersion spectrometry was used to confirm that particles were actually gold. The presence of more than 20 particles on cytoplasm of an individual cell was considered to indicate a positive reaction.

\section{Results}

\section{Blastocyst development}

The recovered blastocysts were spherical on Day 10 and ovoid on Day 12. All specimens on these days had completely bilaminar walls composed of closelyi associated trophectoderm and 
endoderm. A mesodermal layer was forming beneath the embryonic disc by Day 12 and discrete or isolated mesodermal cells were located between the trophectoderm and endoderm adjacent to this region (Pl. 1, Fig. 1).

Columnar trophectodermal cells with short stubby microvilli, rounded nuclei each with a prominent nucleolus, some lipid droplets and rough endoplasmic reticulum were present at the embryonic disc. The remainder of the trophectoderm was composed of squamous to cuboidal cells with elongated nuclei, microfilaments in discrete bundles and concentrations, polyribosomes, rough endoplasmic reticulum and very long thin microvilli on the maternal side. Occasionally, lipid-like material was found sequestered into smooth endoplasmic reticulum.

The endodermal cells were very thin elongated forms that contained some lipid droplets and an intricate network of microfilaments plus sparse mitochondria, rough and smooth endoplasmic reticulum and Golgi complexes. On Day 12, some lipid-like material was observed sequestered into vesicles and the smooth endoplasmic reticulum. The mesodermal cells were irregular in shape with free ribosomes, some rough endoplasmic reticulum, microfilaments, and occasional mitochondria.

Filamentous blastocysts approaching $1 \mathrm{~m}$ in length were recovered on Day 14. Immediately beneath the embryonic disc, the mesoderm had spread completely around the circumference of the tube and separated into parietal and visceral layers giving rise to a distinct yolk-sac tube. In specimens collected about $1 \mathrm{~cm}$ from the disc, the mesoderm was continuous and adjacent to the endoderm or the trophectoderm (P1. 1, Fig. 2) but mesoderm was not observed in specimens collected at $5 \mathrm{~cm}$ from the disc. The cells of the trophectodermal layer in the region of the embryonic disc were columnar while the remainder of the trophectoderm was composed of squamous to cuboidal cells. The structural relationship between the mesodermal and endodermal cells of the developing yolk-sac membrane resulted in the formation of primitive channels ( $\mathrm{Pl}$. 1, Fig. 4) and a few haematoblasts were found within these. The endodermal cells were irregularly shaped with squamous forms associated with trophectoderm and squamous to cuboidal cells adjacent to the mesoderm. Abundant perinuclear profiles of smooth endoplasmic reticulum and lipid sequestered into terminal cisternae were common in the endodermal cells associated with the mesoderm (Pl. 2, Fig. 5). The endoderm and trophectoderm were separated in some regions where the yolk-sac membrane was developing but were still intimately associated in other areas.

The general appearance of the elongated blastocyst and microscopic structure of the trophectoderm on Day 16 were similar to those observed on Day 14. However, the mesoderm had now spread beyond $15 \mathrm{~cm}$ from the embryonic disc in all and beyond $20 \mathrm{~cm}$ in most specimens. The proliferation of mesoderm and exocoelom formation surrounded the circumference of the tube below the embryonic disc but complete separation of endoderm and trophectoderm did not extend beyond this region. Most of the developing yolk-sac membrane therefore exhibited a dorsal vascularized splanchnopleure and an avascular somatopleure ventrally. The splanchnic yolk-sac membrane within $5-10 \mathrm{~cm}$ of the disc had developed a vascular bed consisting of primitive sinusoids delineated by endothelial-like cells. Haematopoiesis was extensive and capillaries with pericyte-like cells were occasionally observed. The association between the mesoderm and endoderm near the extremities of the serosal membrane on Day 16 resembled the primitive channel formation seen on Day 14.

\section{Localization of oestrogens}

Although some steroids would be extracted from tissues during alcohol dehydration, the results indicated that sufficient oestrogens remained, in most specimens, to give a positive reaction with anti-oestrogens. The numbers of gold particles over the cytoplasm of trophectodermal and yolk-sac endodermal cells after treatment with anti-oestrogens and anti-immunoglobulin-gold complex are presented in Table 1. The ultrastructural detail in non-osmicated specimens used for immunocytochemistry was not absolutely clear. However, examination of treated sections and comparisons with similar osmicated material indicated that most of the gold particles accumulated in the apical cytoplasm over organelles that were presumably smooth endoplasmic seticulum or vesicles ( $\mathbf{B l}_{2} \mathbf{L}_{2}$, 
Figs $5 \& 6$ ). Negative results were obtained with each of the following controls: incubation with ovine anti-oestrone followed by anti-porcine IgG-gold complex; incubation with heat-treated ovine anti-oestrone followed by anti-ovine IgG-gold complex; incubation with anti-ovine IgGgold complex without previous treatment with anti-oestrone; and incubation with ovine antioestrone followed by colloidal gold stabilized with polyethylene glycol.

On Day 10, there was a slight positive reaction for oestrone in the cytoplasm of trophectodermal cells (Pl. 3, Fig. 7) but not in the endoderm and no positive reaction for oestradiol-17 $\beta$ in either layer. The presence of both oestrogens was demonstrated in the trophectoderm (Pl. 3, Fig. 8), and in the endoderm that was separated from the disc region by mesoderm on Day 12 . The most intense accumulation of gold particles, and presumably the greatest concentration of steroid, was found for oestrone in the yolk-sac endoderm on Days 14 and 16 (Table 1; Pl. 3, Figs 9 \& 11). A positive reaction for oestradiol-173 (P1. 3, Fig. 10) was also consistently present in both membranes from Days 12 to 16 . The immunocytochemical results were negative in endodermal cells adjacent to positively reacting trophectoderm and in all mesodermal cells.

Extensive development of the yolk-sac membrane occurred by Day 16 and so quantitation of oestrogens in the trophectoderm and yolk-sac endoderm at various distances from the embryonic disc was possible (Table 1). Trophectodermal cells located $1 \mathrm{~cm}$ from the disc gave an intense reaction for both oestrogens. A positive reaction was also present at $10 \mathrm{~cm}$ but results at $20 \mathrm{~cm}$ were

Table 1. Mean \pm s.e.m. number of gold particles located over the cytoplasm of individual trophectodermal and yolk-sac endodermal cells after incubation with anti-oestrogens followed by colloidal gold-labelled anti-immunoglobulin (no. of cells analysed in parentheses)

\begin{tabular}{|c|c|c|c|c|c|}
\hline \multirow{2}{*}{$\begin{array}{l}\text { Day of } \\
\text { gestation }\end{array}$} & \multirow[b]{2}{*}{ Location } & \multicolumn{2}{|c|}{ Trophectoderm } & \multicolumn{2}{|c|}{ Yolk-sac endoderm } \\
\hline & & Oestrone & Oestradiol-17 $\beta$ & Oestrone & Oestradiol-17 $\beta$ \\
\hline 10 & Wall* & $28 \pm 2$ & $<10$ & NP & NP \\
\hline 12 & Wall* & $83 \pm 12(109)$ & $149 \pm 7$ & $213 \pm 15 \quad(105)$ & $78 \pm 14$ \\
\hline 14 & $1 \mathrm{~cm}$ & $198 \pm 11(116)$ & $56 \pm 17$ & $728 \pm 11 \quad(157)$ & $121 \pm 20$ \\
\hline 14 & Tip & $<10 \quad(65)$ & $83 \pm 25$ & NP & NP \\
\hline 16 & $1 \mathrm{~cm}$ & $321 \pm 91$ & $118 \pm 87$ & $1798 \pm 215$ & $540 \pm 312$ \\
\hline 16 & $10 \mathrm{~cm}$ & $91 \pm 2 \quad(102)$ & $29 \pm 1$ & $746 \pm 29$ & $138 \pm 126$ \\
\hline 16 & $20 \mathrm{~cm}$ & $10 \pm 6$ & $<10^{-}$ & $270 \pm 11 \quad(106)$ & $59 \pm 103$ \\
\hline
\end{tabular}

* Sections obtained from bilaminar walls of spherical blastocyst of Day 10 and ovoid blastocyst on Day 12. $\mathrm{NP}=$ not present.

\section{PLATE 1}

Fig. 1. Lateral edge of the embryonic disc from a Day 12 blastocyst showing presence of mesoderm (M) between the disc and underlying endoderm $(E) . \times 645$.

Fig. 2. Cross-section through a filamentous pig blastocyst, $1 \mathrm{~cm}$ from the embryonic disc on Day 14, showing the splanchnic yolk-sac membrane (sp) as a ribbon running diagonally across the blastocyst separating the blastocoelomic cavity into exocoelom (ex) and archenteron (ar). The bilaminar wall of the exocoelom is closely associated trophectoderm and mesoderm (tm) while the serosal yolk-sac membrane (se) is formed by endoderm and trophectoderm. The separation of endoderm and trophectoderm at the bottom of the section is probably an artefact. $\times 30$.

Fig. 3. Flattened trophectodermal cells $(T)$ closely associated with very thin endodermal cells (E), typical of most regions of the chorionic vesicle on Day 14. $\times 4375$.

Fig. 4. Splanchnic yolk-sac membrane on Day 14 with primitive vascular channels forming between the endoderm (E) and mesoderm (M). $\times 3250$. 
PLATE 1
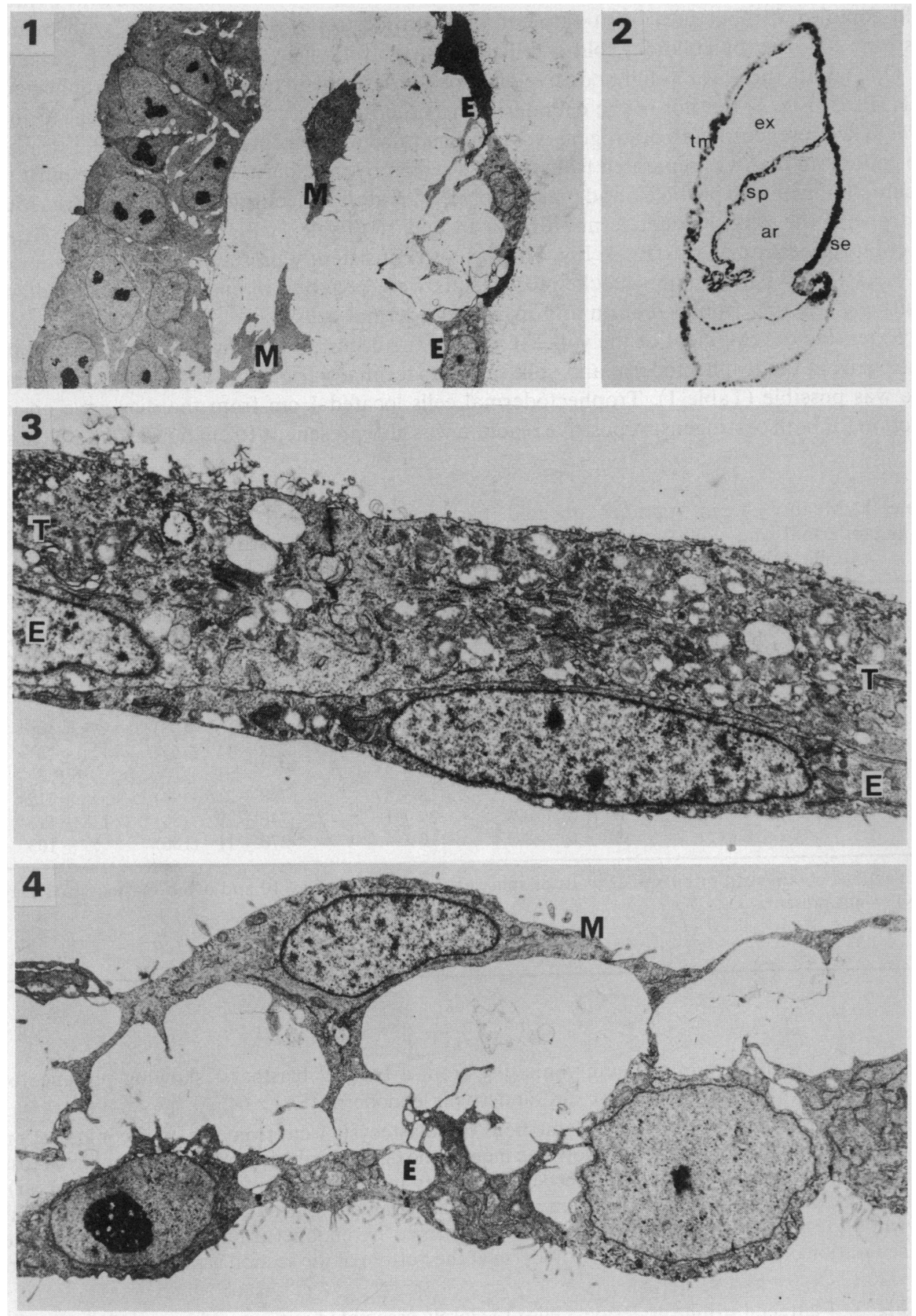

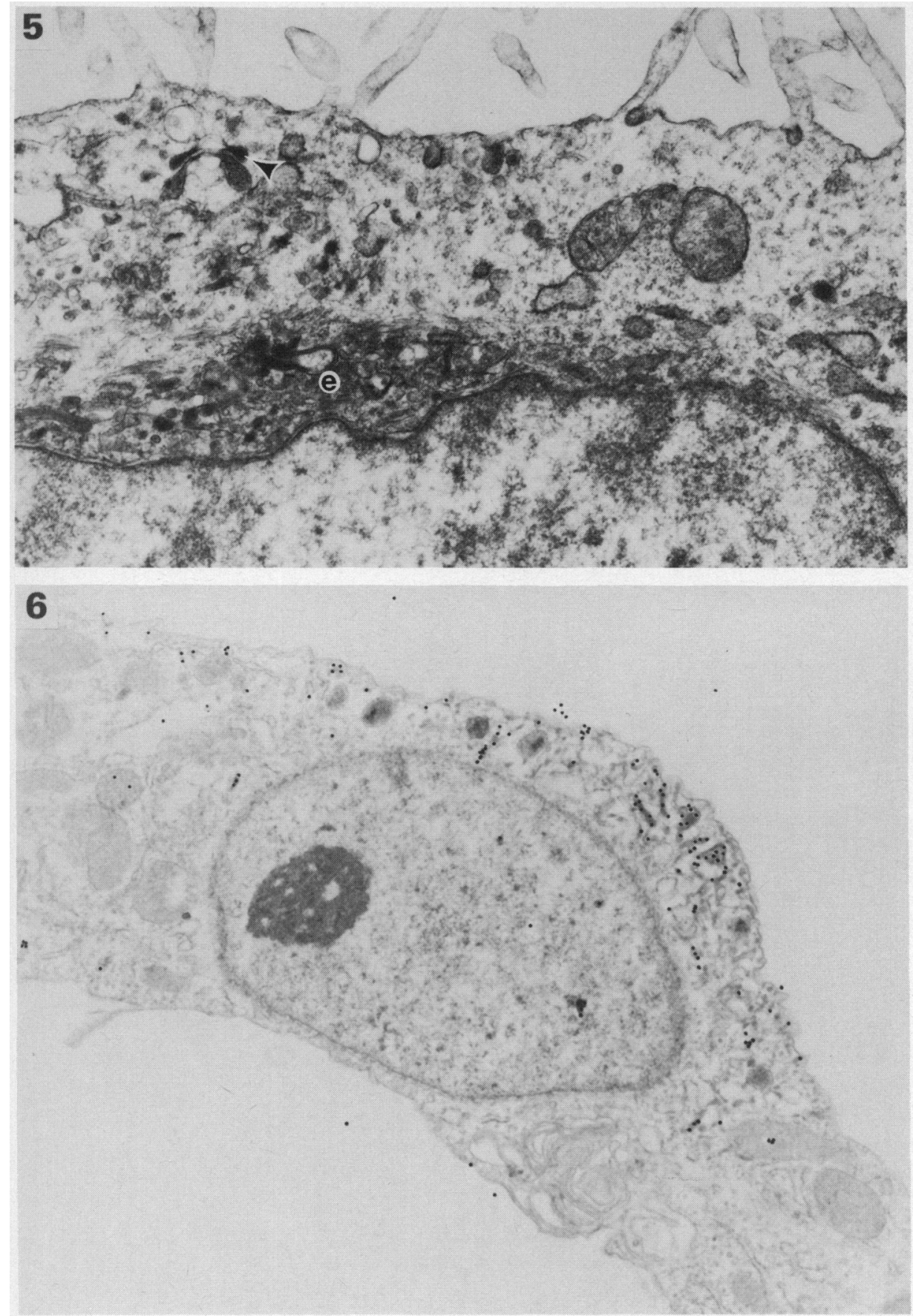

Fig. 5. Apical portion of a Day-14 endodermal cell illustrating profiles of smooth endoplasmic reticulum in the perinuclear region (e) and lipid sequestered in the terminal cisternae $(\boldsymbol{A})$. Glutaraldehyde-osmium fixation. $\times 17500$.

Fig. 6. Electron micrograph of a yolk-sac endodermal cell on Day 14 showing apical localization of gold particles. The section was incubated with ovine anti-oestrone followed by colloidal gold-labelled anti-ovine immunoglobulin. Glutaraldehyde fixation. $\times 10500$. 

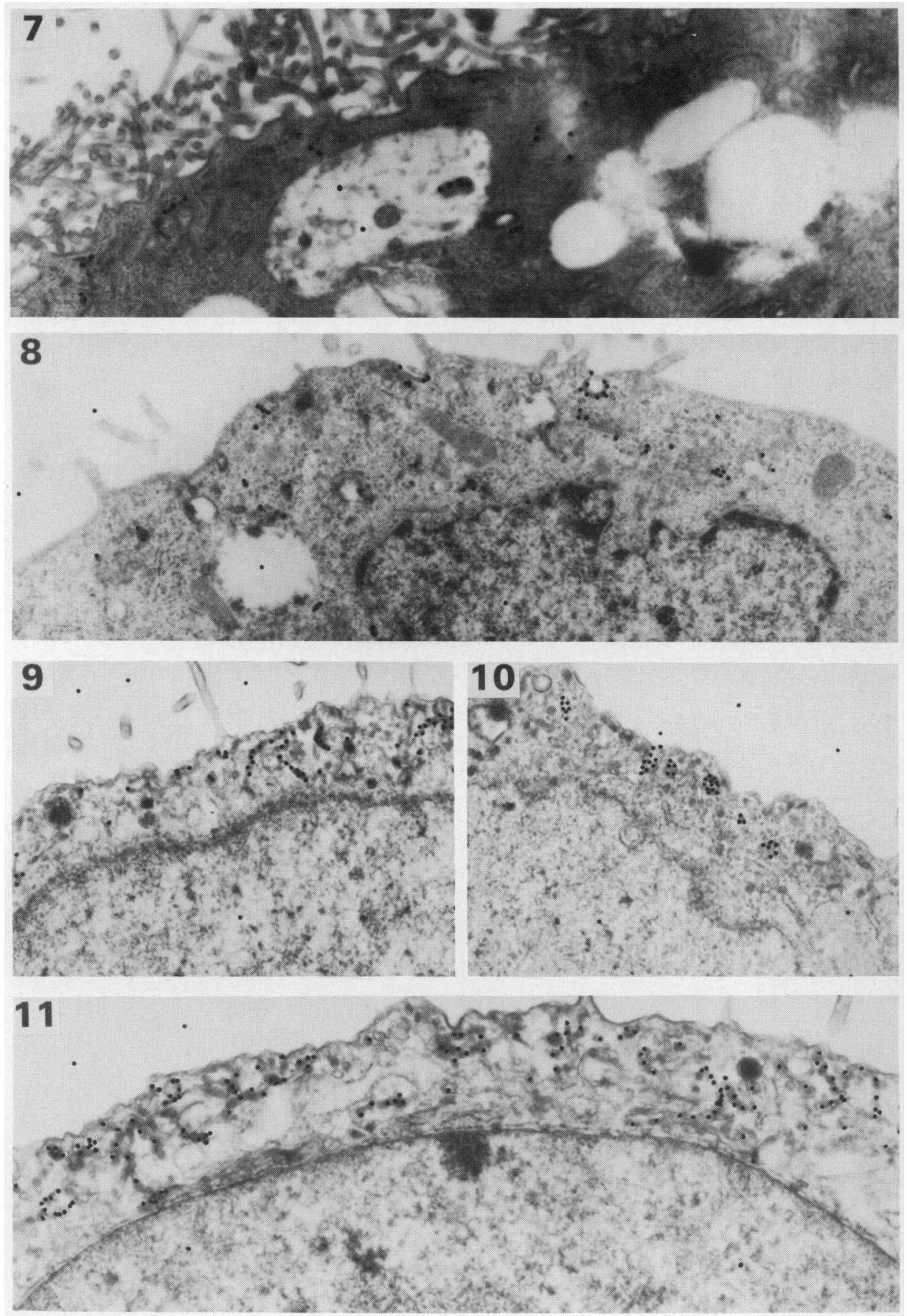
negative. Particle counts in the yolk-sac endoderm indicated substantial quantities of oestrone and oestradiol-17 $\beta$ near the disc with progressively decreasing concentrations distally.

The large standard errors associated with means for oestradiol-17 $\beta$ in the trophectoderm near the disc and in all regions of the yolk-sac endoderm resulted from the extreme variability in counts. The numbers of particles per individual cell ranged from almost zero to values substantially above the means. Most regions contained cells that reacted intensely with the anti-oestrogens while other cells showed no evidence of binding. The immunocytochemical reactions with anti-oestrone and anti-oestradiol- $17 \beta$ were performed on sections from the same blocks but not always on the same cells. Subjective comparisons between the reactions for individual cells subjected to both antibody treatments suggested that many cells produced oestrone and a substantial number of these also produced oestradiol-17 $\beta$, particularly in the trophectoderm on Day 12.

\section{Discussion}

There is considerable variation between development of individual blastocysts within litters (Anderson, 1978) but the rapid transition from the tubular to the filamentous form begins late on Day 12 (Geisert, Brookbank, Roberts \& Bazer, 1982). The blastocysts recovered on Days 10 and 12 in the present study were pre-elongation forms. Their walls were composed of trophectoderm and endoderm in close association but mesoderm was present immediately beneath and adjacent to the embryonic disc on Day 12. The subsequent spread of the mesoderm and expanding exocoelom quickly separated the trilaminar omphalopleur into visceral and parietal components. By Day 14, a few haematoblasts were found in the channels formed between the mesoderm and endoderm of the developing yolk sac, indicating haematopoiesis begins immediately after formation of a splanchnic membrane. The ultrastructural features of the trophectoderm and endoderm were similar to those previously described for pig blastocysts examined on Days 12 or 13 (Hall, Horne \& Perry, 1965; Sasaki, Niimjra \& Ishida, 1979; Geisert et al., 1982) except that lipid was observed in some endodermal and trophectodermal cells.

Within pregnant gilts, uterine venous concentrations of oestradiol-17 $\beta$ were significantly higher than uterine arterial values on Days 11 and 13 and oestrone was higher on Day 15 (Ford, Christenson \& Ford, 1982). A comparison of oestrogen concentrations in samples collected from pregnant and non-pregnant gilts revealed elevated concentrations of oestrone and oestradiol-17 in uterine lymph, but not in arterial plasma, on Days 11, 13 and 15 of gestation (Magness \& Ford, 1982). The immunocytochemical reactions obtained with anti-oestrogens demonstrated the

\section{PLATE 3}

The electron micrographs were obtained from sections of glutaraldehyde-fixed pig blastocyst tissues incubated with ovine anti-oestrone or anti-oestradiol- $17 \beta$ followed by colloidal goldlabelled anti-ovine immunoglobulin.

Fig. 7. Apical surface of trophectodermal cell on Day 10 illustrating some binding of antioestrone in the peripheral cytoplasm. $\times 33250$.

Fig. 8. Apical surface of an endodermal cell on Day 12 located beneath but displaced from the embryonic disc by the developing mesoderm. The section was incubated with anti-oestrone and accumulations of gold particles in the cytoplasm indicate the presence of oestrone. $\times 27560$.

Figs $9 \& 10$. Apical surfaces of endodermal cells of the yolk-sac membrane $1 \mathrm{~cm}$ from the embryonic disc on Day 14. Positive reactions are illustrated for oestrone in Fig. 9 and oestradiol-17 $\beta$ in Fig. 10. $\times 27560$.

Fig. 11. Apical surface of a yolk-sac endodermal cell $5 \mathrm{~cm}$ from the embryonic disc, Day 16 . Concentrations of gold particles in the terminal cisternae of the smooth endoplasmic reticulum indicate the presence of oestrone. $\times 27560$. 
presence of oestrone in the blastocyst wall on Day 10 and of oestrone and oestradiol-17 $\beta$ in the trophectoderm and yolk-sac endoderm of Day 12 and in blastocysts after elongation. The concentrations of gold particles at the apical plasma membrane, illustrated in Pl. 1, Figs 2 and 4, could represent materials leaving the cell or accumulating before entry. Since pig blastocysts produce substantial quantities of oestrogens in vitro and the immunocytochemical reaction was most intense over organelles associated with steroidogenesis, the results indicate that aromatase activity was present in the positively reacting cells. Therefore, both the trophectoderm and yolk-sac produced oestrogens, and gold particles associated with the apical membranes represented exocytosis rather than endocytosis. Some of the oestrogens could pass across the uterine epithelium and into the lymphatics as free steroid while the remainder would be conjugated.

Potential endocrine functions have been attributed to the yolk-sac by previous authors (Zietzschmann \& Krölling, 1955; Michel, 1972; both cited by Tiedemann, 1976). However, although an abundant smooth endoplasmic reticulum was present in endothelial cells of the cat yolk-sac between Days 25 and 38, only a faint reaction for 17/-hydroxysteroid dehydrogenase and no evidence of $3 \beta$-hydroxysteroid dehydrogenase activity was detected. Steroid metabolism rather than synthesis was therefore presumed in this species (Tiedemann, 1976). Pig conceptuses synthesize substantially greater amounts of oestrogen than do cat conceptuses during early gestation (Gadsby, Heap \& Burton, 1980) and both $3 \beta$ - and $17 \beta$-hydroxysteroid activity can be demonstrated in the pig trophectoderm on Day 12 (Flood, 1974). From Day 12 onward, the utilization of 17 $\beta$ hydroxy substrates by trophectoderm declines, indicating a change in the pattern of steroid metabolism within this tissue (Flood, 1974). Since oestrogen production by pig blastocysts increases dramatically during attachment (Robertson \& King, 1974; Heap, Perry, Gadsby \& Burton, 1975; Perry et al., 1976) aromatization may be occurring in some other component of the chorionic vesicle. Endodermal cells in the pig yolk-sac on Days 14 and 16 displayed abundant smooth endoplasmic reticulum and lipid sequestration, as observed in many other steroid-producing cells. The specific binding of anti-oestrone-gold complex to material within the cytoplasm of yolk-sac endoderm indicated the presence of substantial quantities of oestrone in this membrane. The pig yolk-sac may therefore be the principal site of steroidogenesis at this stage of development. Whenever standard errors were included in the results, the variability associated with in-vitro production of oestrogens by cultured pig blastocyst material collected between Days 14 to 18 of gestation is quite large (Heap et al., 1975; Perry et al., 1976; Gadsby et al., 1980). This variability may be related to the amount of synthesizing activity of yolk-sac membrane present in cultured segments of filamentous blastocysts.

We thank the late professor E. C. Amoroso for advice and inspiration; Dr H. A. Robertson for provision of anti-oestrogens; Dr Y. Piche for advice with preparation of gold sols; and B. A. Atkinson, C. A. Skene, J. L. Keys and V. Jaspers-Fayer for technical assistance. Financial support was provided by the Ontario Ministry of Agriculture and Food and by the Natural Science and Engineering Research Council of Canada.

\section{References}

Anderson, L.L. (1978) Growth, protein content and distribution of early pig embryos. Anat. Rec. 190, 143154.

Flood, P.F. (1974) Steroid-metabolizing enzymes in the early pig conceptus and in the related endometrium. J. Endocr. 63, 413-414.

Ford, S.P., Christenson, R.K. \& Ford, J.J. (1982) Uterine blood flow and uterine, venous and luminal concentrations of oestrogens on Days 11,13 and 15 after oestrus in pregnant and non-pregnant sows. $J$. Reprod. Fert. 64, 185-190.
Ford, S.P., Magness, R.R., Farley, D.B. \& Van Orden, D.E. (1982) Local and systemic effect of intrauterine estradiol-17 7 on luteal function of nonpregnant sows. J. Anim. Sci. 55, 657-664.

Frens, G. (1973) Controlled nucleation for the regulation of the particle size in monodisperse gold suspension. Nature, Lond. 241, 20-22.

Gadsby, J.E., Heap, R.B. \& Burton, R.D. (1980) Oestrogen production by blastocysts and early embryonic tissue of various species. J. Reprod. Fert. 60, 409-417.

Downloaded from Bioscientifica.com at 04/26/2023 12:22:56PM 
Geisert, R.D., Brookbank, J.W., Roberts, R.M. \& Bazer, F.W. (1982) Establishment of pregnancy in the pig II. Cellular remodelling of the porcine blastocyst during elongation on Day 12 of pregnancy. Biol. Reprod. 27, 941-955.

Geoghegan, W.D. \& Ackerman, G.A. (1977) Absorption of horseradish peroxidase ovomucoid and antiimmunoglobulin to colloidal gold for the indirect detection of concanavalin $\mathbf{A}$ wheat germ agglutinin and goat anti-human immunoglobulin $G$ on cell surfaces at the electron microscope level: a new method, theory and application. J. Histochem. Cytochem. 25, 1187-1200.

Hall, F.J., Horne, R.W. \& Perry, J.S. (1965) Electron microscope observations on the structure of cytoplasmic filaments in the pig blastocyst. $J l R$. microsc. Soc. 84, 143-154.

Heap, R.B., Perry, J.S., Gadsby, J.E. \& Burton, R.D. (1975) Endocrine activities of the blastocyst and early embryonic tissue in the pig. Biochem. Soc. Trans. 3 1183-1188.

Larson, L.I. (1979) Simultaneous ultrastructural demonstration of multiple peptides in endocrine cells by a novel immunocytochemical method. Nature, Lond. 282, 743-746.

Magness, R.R. \& Ford, S.P. (1982) Steroid concentrations in uterine lymph and uterine arterial plasma of gilts during the estrous cycle and early pregnancy. Biol. Reprod. 27, 871-877.
Perry, J.S., Heap, R.B. \& Amoroso, E.C. (1973) Steroid hormone production by pig blastocysts. Nature, Lond. 245, 45-47.

Perry, J.S., Heap, R.B., Burton, R.D. \& Gadsby, J.E. (1976) Endocrinology of the blastocyst and its role in the establishment of pregnancy. J. Reprod. Fert., Suppl. 25, 85-104.

Pope, W.F., Maurer, R.R. \& Stormshak, F. (1982) Intrauterine migration of the porcine embryo: influence of estradiol-17ß and histamine. Biol. Reprod. 27, 575-579.

Robertson, H.A. \& King, G.J. (1974) Peripheral plasma concentrations of progesterone and of oestrogens in the pig at implantation, during pregnancy and parturition. J. Reprod. Fert. 40, 133-142.

Robertson, H.A., Dwyer, R. J. \& King, G.J. (1980) Effect of oestrogen antisera early in gestation on pregnancy maintenance in the pig. J. Reprod. Fert. 58, 115-120.

Sasaki, H., Niimjra, S. \& Ishida, K. (1979) Ultrastructure of blastocyst on day 13 of gestation in the pig. Jap. J. Zootech. Sci. 50, 721-726.

Tiedemann, K. (1976) On the yolk-sac of the cat. Endoderm and mesothelium. Cell Tiss. Res. 173, 109127.

Received 5 June 1984 